\title{
Obesity makes for a big headline
}

A s many writers of news headlines are all too keen to tell us, obesity is an epidemic that has an enormous impact on health care systems throughout the developed world, as it increases the risk for type 2 diabetes, cardiovascular disease, and various other ailments. Media reports on obesity are often alarming, so much so that one recent headline, drawn from statements made by a public health expert in the United Kingdom, equated the threat of obesity with that of terrorism (1).

The "nature versus nurture" debate has been central to the discussion about the rising incidence of obesity. Some consider obesity to be the result of overconsumption of food and limited exercise. Logically, this problem can be fixed by eating less and exercising more. However, recent studies have indicated that things might not be quite as straightforward as this for everyone. Indeed, we now know that many factors contribute to whether a person is likely to become obese if their calorie intake is excessive and that these factors can have very subtle and complex effects.

One factor that influences whether a person is at risk of becoming obese is genetic makeup. During the past two decades, many genes that control appetite, energy expenditure, and fat metabolism have been discovered. In some cases, mutations in single genes can lead to overeating and obesity. However, these often arise in consanguineous relationships and are therefore uncommon. Indeed, the genetics of obesity is complex, and until recently, efforts to identify obesity genes were largely unsuccessful.

One of the genes associated with obesity is fat mass and obesity associated (FTO). The link between a common variant of FTO and obesity was reported in Science just last year, in a study that indicated that $16 \%$ of adults who carried two copies of the high-risk allele weighed $3 \mathrm{~kg}$ more and had a higher risk (approximately 1.67 times) of developing obesity than those without a high-risk allele (2).

How does the abnormal FTO gene variant lead to obesity? Studies in rodents and humans have suggested that FTO regulates food intake and may also con- trol fat metabolism (3). However, a recent publication in the Journal of Clinical Endocrinology o Metabolism found that children who carry the high-risk allele of FTO did not recognize when they were full after a meal and tended to overeat (4). Jane Wardle (professor of Clinical Psychology at University College London and the lead author of the study), told the JCI that the fact that the high-risk FTO allele operates partly through decreased sensitivity to being full is good news, because it means that individuals with this allele might

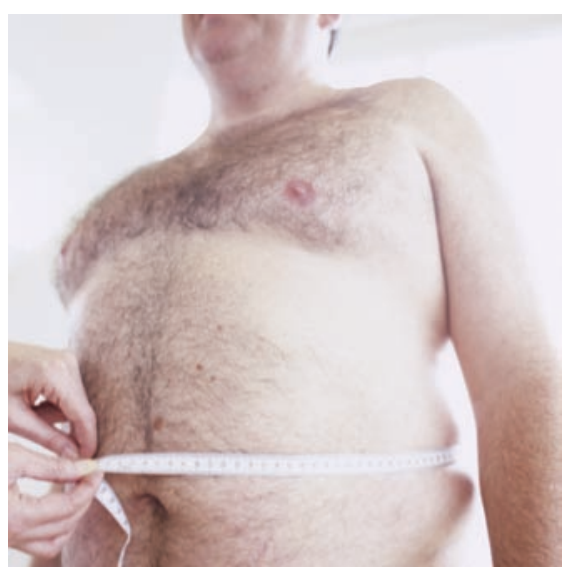

Obesity has an enormous impact on health care systems throughout the developed world. Image credit: Photo Researchers Inc.

be able to learn strategies to combat its effects and thereby reduce their risk of gaining weight. She was also quick to note, however, that "The high-risk FTO allele is associated with an average increase in weight of about $3 \mathrm{~kg}$, so it is not, in itself, a major cause of obesity. There are likely to be many such genes, each exerting a modest effect, and individuals with higher-risk versions of many of these genes will be at considerable risk of obesity."

Research in areas other than genetics, including the biology of fat cells, is also providing new insight into factors that might influence an individual's risk of becoming obese. Earlier this year, a study published in Nature indicated that in adulthood, the number of fat cells in the human body remains constant, even after the loss of a substantial amount of weight (5). The researchers found that weight loss was instead associated with a decrease in the size of the fat cells. Kirsty Spalding, the lead author of the study, told the JCI that the fact that fat cell numbers do not decrease following significant weight loss might help explain why many individuals who are obese struggle to keep weight off after losing it - they are not losing the fat cells, but simply reducing their size.

Despite new research identifying factors beyond the control of an individual as influencing that person's risk of becoming obese, the debate surrounding the causation of obesity and what to do about it is likely to continue. For those who favor an environmental/behavioral etiology, the rational explanation is the first law of thermodynamics, whereby energy intake equals energy expenditure; obesity results when energy intake exceeds expenditure. However, as Rexford Ahima (an expert in CNS regulation of body weight and energy balance at the University of Pennsylvania) summed up nicely for the JCI, "The notion that 'a calorie is a calorie' is attractive but fails to address the complexity of energy metabolism and how excess fat storage leads to disease. Given that most people consume more calories than they expend, it is remarkable that some manage to stay thin. Beyond the headlines, the fact remains that obesity is a complex trait, and progress on this front will require greater understanding of gene-environment interactions."

\section{Karen Honey}

1. Obesity 'equal to terror threat.' 2008 August 14. BBC News. http://news.bbc.co.uk/1/hi/health/ 7559420.stm.

2. Frayling, T.M., et al. 2007. A common variant in the FTO gene is associated with body mass index and predisposes to childhood and adult obesity. Science. 316:889-894.

3. Gerken, T., et al. 2007. The obesity-associated FTO gene encodes a 2-oxoglutarate-dependent nucleic acid demethylase. Science. 318:1469-1472.

4. Wardle, J., et al. 2008. Obesity-associated genetic variation in FTO is associated with diminished satiety. J. Clin. Endocrinol. Metab. 93:3640-3643.

5. Spalding, K.L., et al. 2008. Dynamics of fat cell turnover in humans. Nature. 453:783-787. 